\title{
5. Allies and competitors: private schools and the state in China ${ }^{1}$
}

\section{Barbara Schulte}

\section{INTRODUCTION}

The Chinese education system is usually not associated with private schools. In China's recent history since the communist take-over in 1949, schools have not witnessed any larger privatization waves, despite the fact that the Chinese economy went through an extensive liberalization and privatization in the 1980s and 1990s. On the contrary, the most attractive schools (and universities) are overwhelmingly in public hands. This public stronghold in education signals both the power of the state over allotting life chances, and the state's willingness to retain sovereignty over the main instruments of nation-state socialization.

However, contrary to what one might expect from an at least nominally socialist state, private schools have never been completely erased from the educational landscape. In the 1950s and 1960s, so-called 'schools run by the people', minban schools, were established - the common term to refer to private schools even today. This was done in order to complement the at the time insufficient state system, particularly in the more remote, rural regions. These schools were joined, in the 1980s, by private schools that catered to a new clientele in the cities: largely migrant families from the countryside who lacked a local residence permit to be allowed into public schools. ${ }^{2}$ Often, these schools teach also more

\footnotetext{
1 This work was generously supported by the The Swedish Foundation for Humanities and Social Sciences under Grant P11-0390:1.

2 China has a strict internal migration policy, which makes it difficult for migrants in bigger cities to obtain a local residence permit (hukou). Local residency
} 
specific, vocational skills, particularly beyond the nine years of compulsory education (cf. Kwong, 1997).

Thus, at the same time as the rural minban schools were to be gradually phased out to be replaced by accredited public schools, rural-urban migration caused a new type of privately run school to appear: urban schools for migrant children. This development was smoothed by a generally more favourable policy towards private businesses after the so-called 'Southern Tour' in 1992, on which former leader Deng Xiaoping stressed the importance of economic reform. Particularly from the second half of the 1990s onwards, yet another type of private schools has begun to emerge: schools that niche themselves with specific profiles, targeting families with demands that the public system is unable to satisfy, and charging at times considerable fees.

The terms 'private school', or 'people-run school', as used in the Chinese context hence denote a wide variety of schools, reaching from schools for poor rural children to those for migrant children with external residency, to schools for children from the middle and upper classes seeking an education beyond the ordinary. This chapter will provide an overview of these schools, as well as look at private school entrepreneurs and the clientele served by these schools. ${ }^{3}$ The conclusion discusses to what extent private schools can be considered allies or competitors of the state education system.

The chapter is based on fieldwork conducted in the cities of Beijing and Kunming, and in the province of Zhejiang, between 2010 and 2015. Data were collected in participant observation at 17 private schools, and 62 semi-structured interviews with school founders, school principals, and teachers at private schools, as well as with local stakeholders in the private education business and

is connected to a whole range of social welfare services, including education. Children of any residency are entitled by law to attend their local school, even without a permit. However, in practice children still experience formal and informal exclusion: prohibitive fees, complex paperwork, mobbing and ostracism, etc.; on hukou and education in China, see e.g., Liu, Holmes, and Albright (2015); Zhang and Luo (2015); Zhou and Wang (2016).

3 For a more extensive overview, see Schulte (2017). 
representatives of the Chinese Association for Non-Government Education. ${ }^{4}$

\section{PRIVATE RESPONSES TO UNEVEN DEVELOPMENT AND DIVERSIFICATION IN EDUCATION}

In 1986, China passed its Compulsory Education Law, basically guaranteeing nine years (in some regions provisionally eight years) of schooling to the entire school-age population. Private schools were not part of the state's scheme of education for all but emerged nonetheless when the state was unable, or unwilling, to provide nationwide education. Due to economic liberalization and increased rural-urban migration, private schools of often semi-legal character began to appear. Additionally, the tutoring market gained momentum, producing a growing number of cram schools (cf. Zhang and Bray, 2016). Both genuine private schools and institutions offering extracurricular classes or other types of training were frequently accompanied by reports and rumors regarding embezzlement of funds and fees, poor teacher qualifications, fraud concerning school diploma, dilapidated buildings, and so on. In 1997, the Regulation on the Running of Educational Institutions with Social Resources (State Council, 1997) was passed to bring order into the private educational sector, but many of the problems persisted. In 2003, the Law for Promoting Private Education (NPC, 2002) took a different approach by at least rhetorically welcoming the establishment of private schools in order to complement, and alleviate, the educational burden of the state. Regional governments were now allowed to provide subsidies to private schools, in the form of reduced rent for land, reducing taxes, or remunerating school entrepreneurs.

This regulation led to a number of (probably unintended) consequences. First, the private school market developed increasingly unevenly. Since subsidization is up to the local government, private

4 The Chinese Association for Non-Government Education (Zhongguo Minban Jiaoyu Xiehui) is a nationwide research and lobby network for private education, with regional offices in each province. 
school entrepreneurs face considerable differences when establishing schools. While in some regions the private school business is thriving, in other areas private school entrepreneurs are marginalized or even harassed. As has been shown for the cities of Beijing and Xiamen, for example, the willingness to accept private migrant schools as part of the local school system can differ greatly from city to city: while Beijing has mostly followed a policy of denying accreditation, Xiamen facilitated these schools' integration if they fulfilled certain quality criteria (Wang, 2008). Given the insufficient state provision particularly for migrant children, a hostile attitude towards educational entrepreneurs can lead to children being completely excluded from schooling; conversely, an overly friendly embrace of private schools can also result in an illegitimate outsourcing of state responsibility to the private sector. In the latter case, the state has clearly failed to execute its mandate to provide education for all.

Second, the leeway given to local governments has been a source of corruption, or at least has led to an insufficiently motivated distribution of funds and subsidies. As the author's fieldwork in Zhejiang Province has shown, even within one and the same school district, private schools profit very differently from subsidies, even if these subsidies are granted by local regulations. Those schools that are advantaged in terms of subsidies or preferential tax policies often tend to be in the hands of school leaders who have friendly ties with the local government. A number of private school entrepreneurs had previously worked in the public administration, so they are in a much more favourable position to mobilize their previous connections for facilitating their businesses, compared to competitors with no government ties.

Third, the details of profit-generation are only insufficiently regulated in the law. Legally, private school entrepreneurs are entitled to a so-called 'reasonable return' of investment. However, how to define and calculate what is 'reasonable' is left to local negotiations and friendship ties, or other forms of social capital. Again, this has led to a differential treatment of entrepreneurs. Some are much more successful in diverting money into their own pockets, mostly at the expense of the fee-paying families.

Private schools in China constitute a minority, but their numbers have been growing steadily. In contrast, the numbers of public schools have been decreasing, mainly due to shrinking age cohorts 
because of the one-child policy. Consequently, the share of students attending a private school has increased considerably between 2003 and 2016 (Figure 5.1). Today, 7.1 per cent of students are enrolled at a private school at the primary level; for the lower and upper secondary levels, these shares are 11 per cent and 6.6 per cent, respectively. ${ }^{5}$ The decrease of private school students at the upper secondary level is probably due to the fact that upon completion of grade nine, most students with external residency have to move back to their places of origin in order to prepare for the university entrance examination (UEE). Although a number of provinces have relaxed their UEE policies, now also allowing external students to participate, the practice of migrating back to their home provinces is still widespread among migrant students (Ling, 2017).

The presence of private institutions is considerably larger in preschool and higher education: 35.6 per cent of kindergarten children attend private institutions, and 14.6 per cent of students in higher education have chosen a private university or college. This is mainly due to the fact that preschool and higher education have expanded massively over the past decades, at the same time as the provision of mass education at these two levels is not considered a part of the state's educational mandate. Additionally, the decreased number of state-owned enterprises, which used to run their own kindergartens, and the increasing hunger for tertiary degrees in order to adequately compete in the job market have boosted private entrepreneurship at these levels.

These numbers, however, say nothing about what type of private school is represented to what extent in the statistics. There is no further specification as to the schools' fees and revenues, or their locations and clientele. Moreover, we can assume that a number of migrant schools have not been accredited, or have lost their accreditation, and thus do not appear in the statistics at all, even when they continue to enroll children. In a sense, the diversity of Chinese private schools points to the fact that China is both a developing and developed country at the same time. While, for example, high-fee schools resemble Western elite private schools, the low-fee schools are more similar to the situation in some South

5 In absolute numbers, there are 5,975 private primary schools (compared to 177,600 public institutions), 5,085 private lower secondary schools (public: 52,100), and 2,787 private upper secondary schools (public: 24,700). 


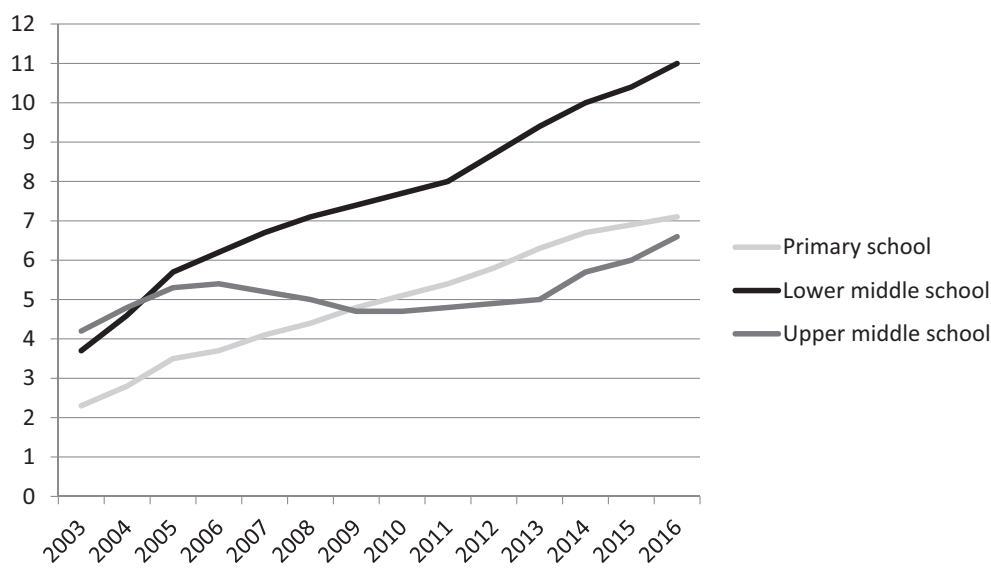

Source: Annual Statistical Reports of the Ministry of Education of the People's Republic of China.

\section{Figure 5.1 Percentage of students enrolled at private schools between 2003 and 2016}

Asian or African regions, where the insufficiency of state-funding has caused families to invest in low-fee private alternatives (see e.g., the overview in Macpherson, Robertson and Walford, 2014). Within the medium-fee sector, private schools can be further divided into subtypes, so that we can overall speak of five different types of private schools in China:

1. Low-fee schools that primarily enroll children from migrant families who do not have local residency. These schools are frequently run by migrants themselves, and often assemble children whose families originate from the same area. They are usually badly equipped both in terms of physical and financial resources and in terms of qualified teachers. They are also among the most vulnerable types of schools, often facing the risk of being closed down by the local authorities. As mentioned above, some city governments have developed more welcoming policies towards these schools, as they have realized that these schools could be utilized at least temporarily to manage the large influx of migrant children. 
2. Medium-fee schools attached to public schools. These private 'siblings' to public schools are examples of the occasionally blurred boundaries between public and private institutions. They were established when there was more demand for places than the respective public school could supply, and they usually retain the name of the public school in their names. These fee-charging siblings thus profit from the public school's name and good reputation. Even though public and private siblings are supposed to operate economically independently from each other, this regulation is not always followed.

3. Medium-fee schools run by individuals. Even these schools serve proportionally many families with external residency but usually attract with a specific school profile (e.g., pedagogical mission, artistic profile, or focus on particular subjects). Having gained accreditation from the local government, they are often chosen by families as the better alternative to the local public school, particularly in run-down areas. Thus, even though these schools may not be able to compete with prestigious public schools, families with no access to highquality public schools prioritize these private schools over the available public option.

4. Medium-fee schools run by corporations. There are essentially two types of corporations running private schools in China: educational corporations are usually the outgrowth of the preceding type, individual entrepreneurial engagement. Entrepreneurs who are successful with their first school do usually not expand that school but register a corporation to establish more schools, often at different levels. Many successful private primary schools, for example, recruit from kindergartens run by the same corporation. The second type of corporations are real-estate companies in charge of gated communities. These companies are required by law to provide compulsory education. The fees charged for school enrolment are comparatively low but are conditioned on buying a (high-priced) apartment on the compound. The better these schools are, the more can be charged for the apartments. In the cases visited during the fieldwork, square metre prices could be raised by tenfold within a few years, which was 
attributed mainly to the efforts invested in high-quality education. Thus, profit is generated not directly from running private schools, but indirectly by tying school enrolment to real-estate purchase. ${ }^{6}$

5. High-fee schools, often with an international profile, and frequently run as Chinese-foreign joint ventures. These schools can be considered elite schools and charge substantial fees. They serve families from the upper class as well as expatriate families, and mostly do not even offer a Chinese degree. Usually, students are prepared for studying overseas upon graduation.

\section{SCHOOL ENTREPRENEURS AND EDUCATIONAL CLIENTELE}

Private education may be simply regarded as a business: the opportunity to extract profit from education. However, this common-sense understanding needs to be nuanced in a context where, first, the state does not provide education for all (in spite of a law to do so); and second, the quality of education varies considerably, excluding the large majority from high-quality public education. As Carnoy (2006) has illustrated with the examples of Chilean privatization and the Black Panther School in Oakland, private actors in education can have very different motives and effects: they may constitute the extension of a government policy to commodify, stratify and eventually de-solidarize a society; but they may also represent grassroots initiatives that seek educational empowerment vis-à-vis an oppressive state. Chinese educational entrepreneurs do not clearly belong to one or the other category; depending on the school, entrepreneurs can be either seen as coopted by the state, or as challenging state education (to a moderate extent). In their self-perception, school founders overwhelmingly perceive themselves as moral entrepreneurs who serve

6 Interestingly, this presents a case where the common logic is turned around. While usually high-quality living areas have the better schools as a side-effect of economic, cultural, and social capital accumulation (see e.g., Fack and Grenet, 2010), in the Chinese case of gated communities, good schools are used as a selling point for (otherwise less attractive) apartments. 
the society rather than exploit it. This philanthropy is based on the following arguments:

1. More choice. Entrepreneurs argue that private schools enlarge the educational options even for families with limited economic, cultural, social, political, or geographic capital. Families thus become empowered to script their own life trajectories and plan their careers without being constrained by lower-quality, state-provided options.

2. Taking care of the less privileged. Both migrant children even those coming from affluent families but with external residency - and children with learning difficulties are not sufficiently taken care of within the state system. Private entrepreneurs see themselves as assuming responsibility for these marginalized groups.

3. Unburdening the state. Private entrepreneurs claim that without private entrepreneurialism, and the resources it is capable of mobilizing, the state would have to carry a much higher burden for education. Private school entrepreneurs thus depict themselves as unburdening and complementing the public system.

4. Moralizing education. School entrepreneurs like to claim that public education mainly aims to 'cram' students with examoriented knowledge. In contrast, private schools are represented as providing a more student-centred, holistically oriented, and morally enriched education.

5. Adding transparency. Private school entrepreneurs frequently describe their businesses as more transparent, rational, and quality-oriented compared to their public counterparts. They see the reason for this difference in the healthiness of market dynamics: wasteful or inefficient school governance eventually leads to closing down a private school.

6. Making knowledge useful. Since private school entrepreneurs need to take into consideration the career prospects of the school's graduates, they claim that the knowledge taught at their schools is more applicable and welcomed in the labour market. They additionally collaborate with local companies in order to facilitate their graduates' entry into the job market. 
Families, on the other hand, have various, sometimes overlapping motives to opt for a private school. Among them, the following are the most pronounced:

1. Getting (better) access. As mentioned, migrant children are often excluded from attending local public schools. Alternatively, they can be directed to a low-quality public school, or lower-quality classes within the local public school. Choosing a private school can thus mean simply obtaining access, or additionally getting access to a better-quality education. At times, also ostracism against migrant children at public schools pushes families to opt for private alternatives.

2. Schooling for the second child. Until recently, China has practiced a one-child policy, making it extremely difficult for a family to enroll their second (or third) child at a public school. Private schools have therefore been the natural choice for families with more than one child. Many private schools have a substantial number of siblings in their student population, while siblings are rare phenomena at public schools. Recent relaxations of the one-child policy may make this motive obsolete.

3. Alternative to cram schools. Even though Chinese examinations went through some reforms, they still require extensive rote learning. Usually, parents enroll their children at private tutoring schools to drill them for examinations. Full-time private schools often offer tutoring services on campus, where the teachers from the morning classes tutor their students in the afternoons. Children at private schools do therefore no longer need to additionally enroll at cram schools but can get their education (and cramming) all from one school.

4. Going global. International schools offer the convenience of escaping the drill for Chinese examinations. Perhaps due to their high fees and 'softer' curriculum, they are also among those schools that have received most criticism from the public, who have accused these high-fee schools of being 'schools for the nobility' (Yan, 2016). In common parlance, the international track is called the 'international exit' solution. Such a solution however means that these schools' graduates will not be able to study at Chinese universities. 
5. The gated-community school as a one-stop shop. Living in a gated community and enrolling one's child in the community's school kills several birds with one stone. Private gated communities provide access irrespective of administrative residence status, accept families with more than one child, and offer both tutoring classes and other activities in the afternoon. Many communities also offer an international track, thus combining all of the previous aspects in one solution. Besides, parents no longer need to chauffeur their children, as their children can basically stay within the compound all day long.

6. Looking for care. Public schools usually see themselves as serving the mainstream. They have only insufficient resources and little understanding for students who are in greater need of care and attention. A number of private schools have found a niche catering to students with diverse educational and psychological needs. These schools do usually not graduate the academically most outstanding students, but they provide these students with a general degree, which spares the families from the public shame that the certificate from a special school would entail.

7. Avoiding vocational school. Vocational schools have a substantially lower reputation than general schools; however, at the upper secondary level they constitute half of all schools. Choosing a private school can therefore help families avoid a school whose diploma is only little valued in the job market. Even though the respective private school may have a lower reputation than the local public school, its leaving certificate still signals the quality of a generally oriented, rather than a vocational, education.

As these various motives illustrate, to opt for a private school is neither always a desperate action to gain access to schooling at all; nor necessarily a luxury act of purchasing an elite education. Most private alternatives in urban China are situated in between: chosen by families with some resources, who nonetheless do not enjoy the same privileges as those with high amounts of political, social, and geographic capital (see also Young, 2017). 


\section{CONCLUSION: COOPTATION OR COMPETITION?}

In general, private education has never received much sympathy from the central Chinese government. The rather vague regulation and continuing reluctance in many areas to allow for, and accredit, private schools indicate that there is little appetite to permitting any large-scale, long-term privatization in education. From the state's perspective, private education serves two purposes. First, it can be used as a temporary solution for the poorer regions and strata, as long as state provision is insufficient. Second, private education may, again at least temporarily, pacify those groups in society who would otherwise feel marginalized or deprived. Particularly families with considerable financial resources but lacking local residency can thus be coopted into the system - even more so as these families are used to relying on their private economic resources for purchasing lifestyles of their own choice.

A recent change in the political attitude towards private education seems to indicate that the limits of state-society cooptation have been reached. In October 2016, the People's National Congress passed an amendment to the Law for Promoting Private Education. From 2017 onwards, private schools are no longer allowed to operate within compulsory education if they are for-profit (NPC, 2016). This has raised concerns that migrant families will be left without any educational options, unless the state intervenes, and invests, more drastically than is the case at present. Does this change in policy mean that the alliance of state and private actors to make education more inclusive, or more diverse, has been dissolved?

At first glance, this recent move can be interpreted as the state's comeback: a clear signal that the state is no longer willing to leave the mission of a nationwide, all-encompassing education to private actors. Such a move coincides also with more general official announcements to make education more equal, and provide highquality education for all. However, the new amendment only bans for-profit private schools from compulsory education; non-profit, or philanthropic, actors are still allowed. One reason for this could be some sort of moral motivation: making it clear to the population that generating profit from something that is to serve the public good is no longer acceptable. Given the widespread perception in 
public opinion that high-fee schools are institutions rife with greed and embezzlement of school funds, such a moral motivation is not improbable. Again, a moral-ideological re-orientation is also palpable in more general political statements issued by present leader $\mathrm{Xi}$ Jinping, and forbidding for-profit schools may be one consequence from this moralization of politics.

However, if one looks at what kind of schools operate with profit, another interpretation becomes even more convincing. Schools for the poor naturally have no particularly large profit margins. It is the schools for the middle class and above that are the most lucrative businesses. As has been pointed out in the introduction, the best schools are usually public schools. This view has also been reiterated in the literature: Chinese researchers find students of private schools consistently performing lower than their public school peers (e.g., Liu, 2011). The PISA data for Shanghai, however, cannot confirm these findings: student performance at private schools is found to be higher than at public schools. Only when the economic, cultural, and social status of schools and students are taken into consideration, public schools outperform their private peers; that is, public schools succeed better in spurring the performance of lower-status students (OECD, 2013: 56). The most recent PISA data, which besides Shanghai include data for Beijing and the provinces of Jiangsu and Guangdong, also find a slight performance advantage for private school students, when not accounting for status (OECD, 2016: 125 and 143). This means that in wealthy regions like Shanghai, Beijing, Jiangsu, and Guangdong, entrepreneurs have been able to establish private schools that attract a clientele with high economic, cultural, and social status - schools that can actually compare favourably with their public competitors.

No definite conclusions can be drawn from these data; however, the PISA data, as well as the difference between the PISA findings and those reached by Chinese researchers on private schools nationwide, suggest that it is above all the affluent regions where private school students outperform their public school peers. That is, while private schools in poorer regions serve as lower-quality complements to an insufficiently provided state education, private schools in wealthier regions may have begun to constitute better alternatives to state education. This assumption is further supported by media reports that note a performance advantage of private schools in richer provinces like Zhejiang. According to these 
reports, parents are increasingly concerned about the government's reform 'craze' and worry that this may be disadvantageous for their offspring's education and exam performance. Lest their children become 'experimental objects of public reform' (HZJS, 2015), these parents increasingly opt for private schools, who are less prone to truthfully following educational reforms.

There is reason to assume that this voluntary resort to private schooling has raised the government's suspicions. Previously, private education was at best considered a second choice, with the public school defining what good-quality education was. Now that some private schools are emerging as serious competitors, this power imbalance risks changing in favour of private actors. Additionally, a second, better-quality track has potentially disintegrative power: middle- and upper-class families might decide to simply turn their backs on state schools, with implications for the state's leverage to reach and influence these families. If private schools for affluent families are as reform-resistant as is maintained in the above-cited report, Chinese education may even end up with two different systems: a state-provided, reformed system; and a private system based on conventional pedagogy. Both the previous policies of treating private education as a temporary phenomenon which is to complement the state system, and the recent policy change suggest that the Chinese state is not willing to allow for such a disintegration and bifurcation in schooling.

As has been noted above, recent Chinese policy changes, in education and beyond, have been characterized by an increasing re-ideologization, prompting scholars to speak of a 'return of ideology' (Yang, 2014), and to compare the present administration under $\mathrm{Xi}$ Jinping to that of Mao Zedong. In education, this has resulted in attempts to re-centralize teaching content (e.g., by re-centralizing the textbook market), and make education more equal - both in terms of guaranteeing more equal access to education, and reducing various differences and divides among students and schools. It is debatable how noble Xi Jinping's motives for expanding public welfare are (Solinger, 2017); nonetheless, the emphasis on a fatherly, caring government is a legitimating pillar for the present regime. To outsource parts of the public welfare to private actors may cause this pillar to wobble; if these private actors even turn out to be more efficient than the government actors, the pillar may collapse altogether. A fair competition between private 
and public actors is therefore not in the Chinese government's interest. Even more importantly, the increasing emphasis on ideological unity is incompatible with a situation in which families can buy themselves out of the system. Various tensions and plights will continue to exist, pressing parents to reach out for private alternatives. Although some pressures have diminished, such as the one arising from having a second child, others may intensify: increasing competition in the job market, for example, will push graduates to seek distinction through a particular diploma, and the strict household policy will continue to create first and second class citizens. However, as Solinger (2017: 57) concludes regarding the limited effectiveness of anti-poverty programmes in China, the state is prepared to ignore these plights at least to a certain extent, by communicating that these people's 'cause has been downgraded in the interest of other goals'. Thus, allowing for private schools as an alleviating measure may be abolished for the sake of national and ideological unity.

\section{REFERENCES}

Carnoy, M. (2006). Rethinking the comparative - and the international. Comparative Education Review, 50(4), 551-570.

Fack, G. and Grenet, J. (2010). When do better schools raise housing prices? Evidence from Paris public and private schools. Journal of Public Economics, 94, 59-77.

HZJS (Hangzhou Zhongxiaoxue Jiaoxu Shixun) (2015). 2015 Hangzhou minban chuzhong he gongban chuzhong zhongkao chengji duibi [Comparing the 2015 results from middle school entrance examinations among private and public lower middle schools in Hangzhou] (24 June 2015) Bendibao. Retrieved on 22 May 2018 from http://hz.bendibao.com/edu/ 2015624/56868.shtm

Kwong, J. (1997). The reemergence of private schools in socialist China. Comparative Education Review, 41(3), 244-259.

Ling, M. (2017). Returning to no home: education remigration and displacement in rural China. Anthropological Quarterly, 90(3), 715-742.

Liu, L. (2011). Gongban xuexiao yu minban xuexiao xuesheng kaoshi chengji chayi chengyin de shehui fenxi - yi 2010 nian zhongkao tiyu chengji weili [A society-oriented analysis of the reasons for the difference in examination grades among students from public and private schools - using the 2010 middle school examination grades in physical education as an example]. Xin Kecheng Yanjiu, 230(8), 110-112. 
Liu, T., Holmes, K. and Albright, J. (2015). Urban teachers' perceptions of inclusion of migrant children in the Chinese educational institution: a comparative study. International Journal of Inclusive Education, 19(9), 994-1008.

Macpherson, I., Robertson, S.L. and Walford, G. (eds) (2014). Education, Privatisation and Social Justice: Case Studies from Africa, South Asia and South East Asia. Oxford: Symposium Books.

NPC (National People's Congress of the People's Republic of China) (2002). Zhonghua Renmin Gongheguo Minban Jiaoyu Cujinfa [Law of Promoting Private Education in the People's Republic of China]. Retrieved on 22 May 2018 from http://www.gov.cn/test/2005-07/28/content_17946.htm.

NPC (National People's Congress of the People's Republic of China) (2016). Yiwu jiaoyu bude ban yinglixing minban xuexiao [Compulsory education not allowed to run for-profit private schools] (1 November 2016) Beijing: Renmin Ribao Retrieved on 22 May 2018 from http://www.npc.gov.cn/npc/ xinwen/lfgz/2016-11/01/content_2000338.htm.

OECD. (2013). PISA 2012 Results. What Makes Schools Successful? Resources, Policies and Practices. Paris: OECD Publishing.

OECD. (2016). PISA 2015 Results (Volume II): Policies and Practices for Successful Schools. Paris: OECD Publishing.

Schulte, B. (2017). Private schools in the People's Republic of China: Development, modalities and contradictions. In T. Koinzer, R. Nikolai and F. Waldow (eds), Private Schools and School Choice in Compulsory Education. Global Change and National Challenge (pp. 115-131). Berlin: Springer.

Solinger, D.J. (2017). Manipulating China's 'Minimum Livelihood Guarantee': political shifts in a program for the poor in the period of Xi Jinping. China Perspectives, (2), 47-57.

State Council (1997). Shehui liliang ban xue tiaoli [Regulation on the running of educational institutions with social resources]. (Decree No. 226). Retrieved on 22 May 2018 from http:/www.eduzhai.net/yingyu/615/763/ yingyu_246572.html.

Wang, L. (2008). The marginality of migrant children in the urban Chinese educational system. British Journal of Sociology of Education, 29(6), 691-703.

Yan, D. (2016). Yinglixing minban xuexiao jinru yiwu jiaoyu? [For-profit education prohibited from entering compulsory education?] (5 November 2016) Xinhua. Retrieved on 22 May 2018 from http://news.xinhuanet.com/ yuqing/2016-11/05/c_129352093.htm.

Yang, G. (2014). The return of ideology and the future of Chinese internet policy. Critical Studies in Media Communication, 31(2), 109-113.

Young, N.A.E. (2017). Departing from the beaten path: international schools in China as a response to discrimination and academic failure in the Chinese educational system. Comparative Education, 1-22.

Zhang, D. and Luo, Y. (2015). Social exclusion and the hidden curriculum: the schooling experiences of Chinese rural migrant children in an urban public school. British Journal of Educational Studies, 1-20. 
Zhang, W. and Bray, M. (2016). Micro-neoliberalism in China: public-private interactions at the confluence of mainstream and shadow education. Journal of Education Policy, 1-19.

Zhou, Y. and Wang, D. (2016). Understanding the constraints on the supply of public education to the migrant population in China: evidence from Shanghai. Journal of Contemporary China, 1-16. 